\title{
MICROBIAL POPULATION WITH POTENTIAL TO SIMULTANEOUSLY DEGRADE ORGANOCHLORINE INSECTICIDES
}

\author{
Saghee Madhu Raju ${ }^{1,2 *}$, Rajkumar Bidlan ${ }^{2 \#}$
}

${ }^{1}$ Research Scholar, Rayalaseema University, Kurnool, India

${ }^{2}$ Dr.Bidlan's Research Institute, Hyderabad, India

Received - January 05 , 2018; Revision - April 26, 2018; Accepted - July 17, 2018

Available Online - August 10, 2018

DOI: http://dx.doi.org/10.18006/2018.6(4).690.700

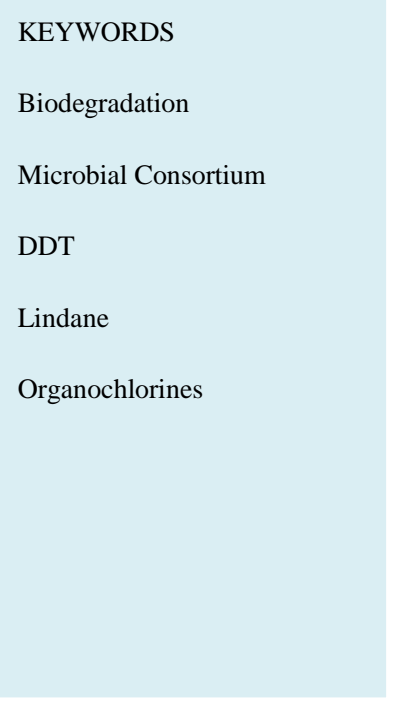

\begin{abstract}
Organochlorine pesticides (OCPs) such as 1,1,1-trichloro-2,2-bis(4-chlorophenyl) ethane (p,p'-DDT) and ${ }_{\gamma}$-hexachlorocyclohexane (Lindane) pose serious health effects to the environment and community. Although both these compounds are prohibited in many parts of the world, their residues were detected in various soil, air and aquatic ecosystems. Currently, research has been carried out on a single pesticide with a single microbe or a consortium with few members for biodegradation of organochlorine pesticides. In the environment, the scenario is different with many other compounds and native flora present that can make the application of single microbe or small consortium difficult to succeed. The current study was initiated to develop a microbial consortium that can act simultaneously degrade and eliminate more than one organochlorine compounds while maintaining its integrity in the environment. In this study, the simultaneous degradation of DDT and Lindane at $10 \mathrm{ppm}, 20 \mathrm{ppm}$ and $30 \mathrm{ppm}$ concentration was studied at $0,24,42,78$ and 92 hours at optimized conditions (pH-7 and OD600 0.075). The enriched consortium could simultaneously degrade $90 \%$ of 10 PPM of DDT and Lindane.The enriched consortium was tested for degrading mixture of organochlorine pesticides with concentrations up to $30 \mathrm{ppm}$ of DDT and Lindane mixture, and demonstrated promising observations that illustrate the usage of the consortium for degrading the OCPS with high efficiency.
\end{abstract}

* Corresponding author

E-mail: madhu.saghee@gmail.com (Saghee Madhu Raju)

\#Present Address: Department of Biotechnology, Delhi Technological University, Shahbad, Daulatpur, Delhi- 110042

Peer review under responsibility of Journal of Experimental Biology and Agricultural Sciences.

Production and Hosting by Horizon Publisher India [HPI] (http://www.horizonpublisherindia.in/).

All rights reserved.
All the article published by Journal of Experimental Biology and Agricultural Sciences is licensed under a Creative Commons Attribution-NonCommercial 4.0 International License Based on a work at www.jebas.org.

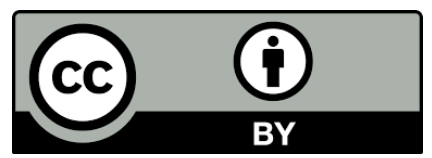




\section{Introduction}

Organochlorine insecticides such as 1,1,1-trichloro-2,2-bis(4chlorophenyl) ethane ( $p, p^{\prime}$-DDT) and $\gamma$-hexachlorocyclohexane (Lindane) have been used in large scale in later part of $20^{\text {th }}$ century primarily for pest control and agricultural purposes (Wasim Aktar et al., 2009). Organochlorine (OC) pesticides are synthetic in nature and are made up of chlorinated hydrocarbon derivatives. These insecticides have acute toxicity and can be bioaccumulated in the food chain leading to heightened pollution levels in environment. Majority of the OCPS are banned in many countries, however their usage is rising in developing countries due to the low cost leading to chemical abuse (Jayaraj et al., 2017).

Targeted research has been conducted using a single OCP molecule, and studies established removal of pesticides in the field level bioremediation. Still no organochlorine pesticide residues are eliminated from the nature leading to their persistence and causing major health issues among the population (Abraham et al., 2014). In current study, a mixed consortium isolated from Indian rivers Yamuna and Godavari, and enriched using DDT and Lindane was used to demonstrate the potential to degrade the organochlorine insecticides (Pandey et al., 2011). The consortium was characterised using advanced genome sequencing system utilizing illumina platform (de Muinck et al. 2017) that identifies even the unrecoverable species in the laboratory environment (Handelsman, 2004).

\section{Materials and Methods}

\subsection{Chemicals}

99.4\% pure $p, p$ '-DDT was donated for research by Hindustan Insecticides Ltd., India while $97 \%$ pure Lindane was purchased from Sigma Aldrich, USA. HPLC grade acetone and ethyl acetate was procured from Merck. Other chemicals used were of analytical grades and purchased from standard manufacturers.

\subsection{Microbial culture and enrichment}

Water samples were collected from two Indian holy rivers Yamuna and Godavari. These samples were subjected to increasing concentrations of two organochlorine pesticides (OCP) 1,1,1-trichloro-2,2-bis-(4-chloro) ethane (DDT) and $\gamma^{-}$ hexachlorocyclohexane (Lindane) over a period of 6 months. Periodically it was tested for the viability of the population through streaking on to nutrient agar (Bidlan \& Manonmani, 2009).

\subsection{Extraction of OCPs}

Samples drawn at every $24 \mathrm{~h}$ were acidified and extracted with equal volume of dichloromethane twice and organic layers pooled after passing through anhydrous sodium sulphate and fluorisil. The residual OCPs were transferred into microfuge tubes after completely drying the dichloromethane and dissolving in a small volume of acetone.

\subsection{Gas Chromatography-Mass Spectrometry Fingerprinting}

Qualitative and quantitative analyses were confirmed with GCMS/MS fingerprinting using Agilent 7000D equipment with triple quad (Abd El-Gawad, 2016). The column HP-5ms (Agilent 19091S EPC) was programmed with pressure 30.797 psi, the flow of $3.1793 \mathrm{~mL} \cdot \mathrm{min}^{-1}$, average Velocity of $54.506 \mathrm{~cm} \cdot \mathrm{s}^{-1}$ and temperature $70^{\circ} \mathrm{C}$ to $280^{\circ} \mathrm{C}$, the sample was electron ionized (EI) with a source temperature of $300^{\circ} \mathrm{C}$. The quantification was done using a standard curve prepared for different amounts of the two OCPs (DDT and Lindane) under the same conditions (Muir \& Sverko, 2006).

\subsection{Genomic DNA extraction}

DNA was isolated using Xcelgen Bacterial gDNA kit with few modifications. Quality of gDNA was checked on $0.8 \%$ agarose gel and quantification was done on Nanodrop 8000 (Blomquist et al., 2013).

\section{Results and Discussion}

\subsection{Consortium}

The microbial population was enriched using long term acclimatization technique where the sample was subjected to mixture of DDT and Lindane. This resulted in a microbial population that was capable for biodegradation of OCP mixtures and contained many types of microorganisms. Some of the strains were isolated by repeated streaking. The samples were spread on LB-agar plates at various stages of enrichment and the petridishes were incubated at room temperature to check vitality (Figure 1).

\subsection{Degradation of DDT-Lindane mixture by the consortium}

The degradation of mixture of DDT and Lindane at 10, 20 and 30 ppm concentrations was reflected in the TLC plate and confirmed by GCMS/MS fingerprinting. There was a marked reduction in the residual concentration of Lindane in three days of incubation. The amount of DDT also reduced from $0 \mathrm{~h}$ to $96 \mathrm{~h}$. Gas Liquid Chromatograms show that the retention time of Lindane was 13.3 min while that of $p$, $p^{\prime}$-DDT was 26.9 min under the conditions of analyses. Figure 2 and 3 gives the chromatograms of the experiment with $10 \mathrm{ppm}$ of each DDT and lindane in the broth. Figure 3 and 4 gives the chromatograms of the experiment with $20 \mathrm{ppm}$ of each DDT and Lindane in the broth. Figure 5 and 6 gives the chromatograms of the experiment with $30 \mathrm{ppm}$ of each DDT and Lindane in the broth.The enriched consortium could degrade $95 \%$ of $10 \mathrm{ppm}$ Lindane and DDT in the supplied mixture by the end of 96 h (Figure 7), similar degradation was also observed for 20 PPM and 30 PPM pesticide concentration however at reduced efficacy due to the increase in concentrations of the pesticides (Figure 8-10). 


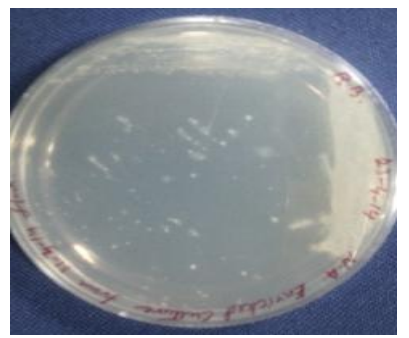

A

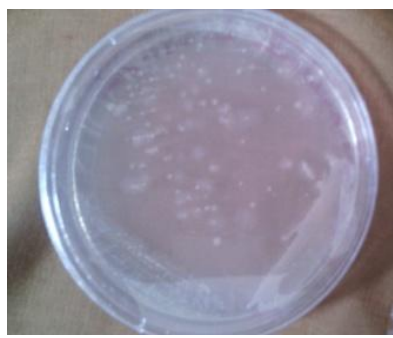

B

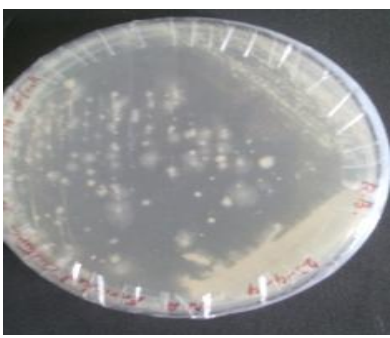

$\mathrm{C}$

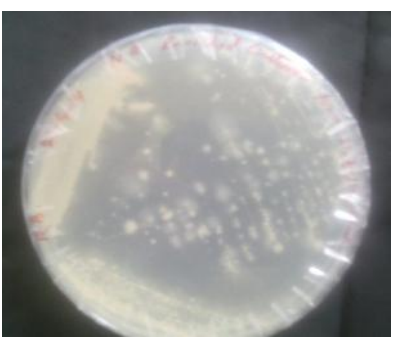

D

Figure 1 Plates after 3 cycles of enrichment with $5 \mathrm{ppm}$ of each pesticide as listed above. (After: $\mathrm{A}=36 \mathrm{H}$ of incubation; $\mathrm{B}=60 \mathrm{H}$ of incubation; $\mathrm{C}=84 \mathrm{H}$ of incubation; $\mathrm{D}=100 \mathrm{H}$ of incubation)

Sample Chromatogram
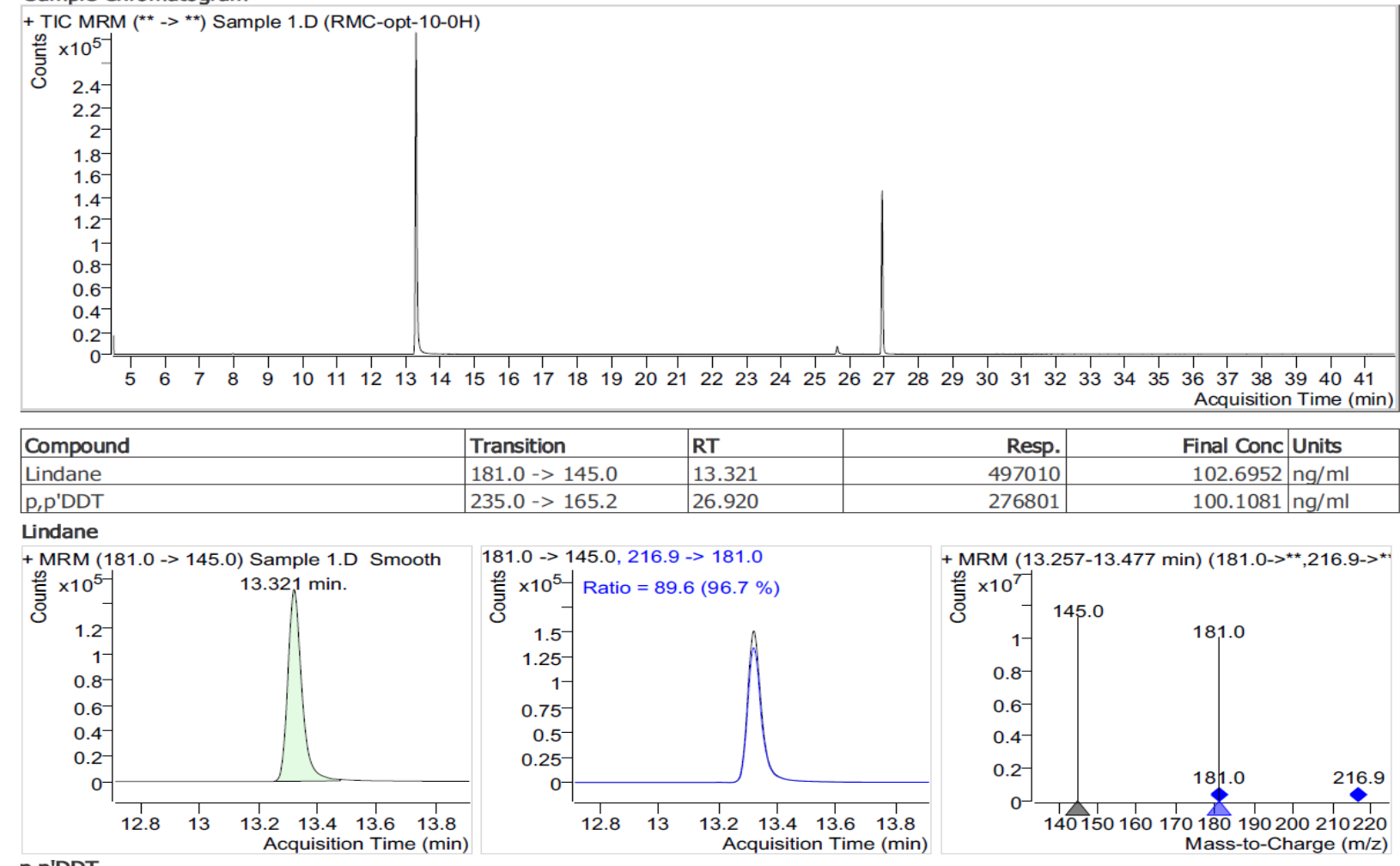

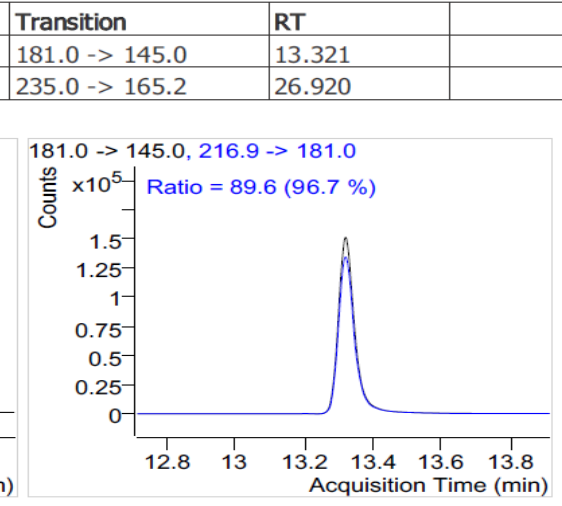
Acquisition Time (min)
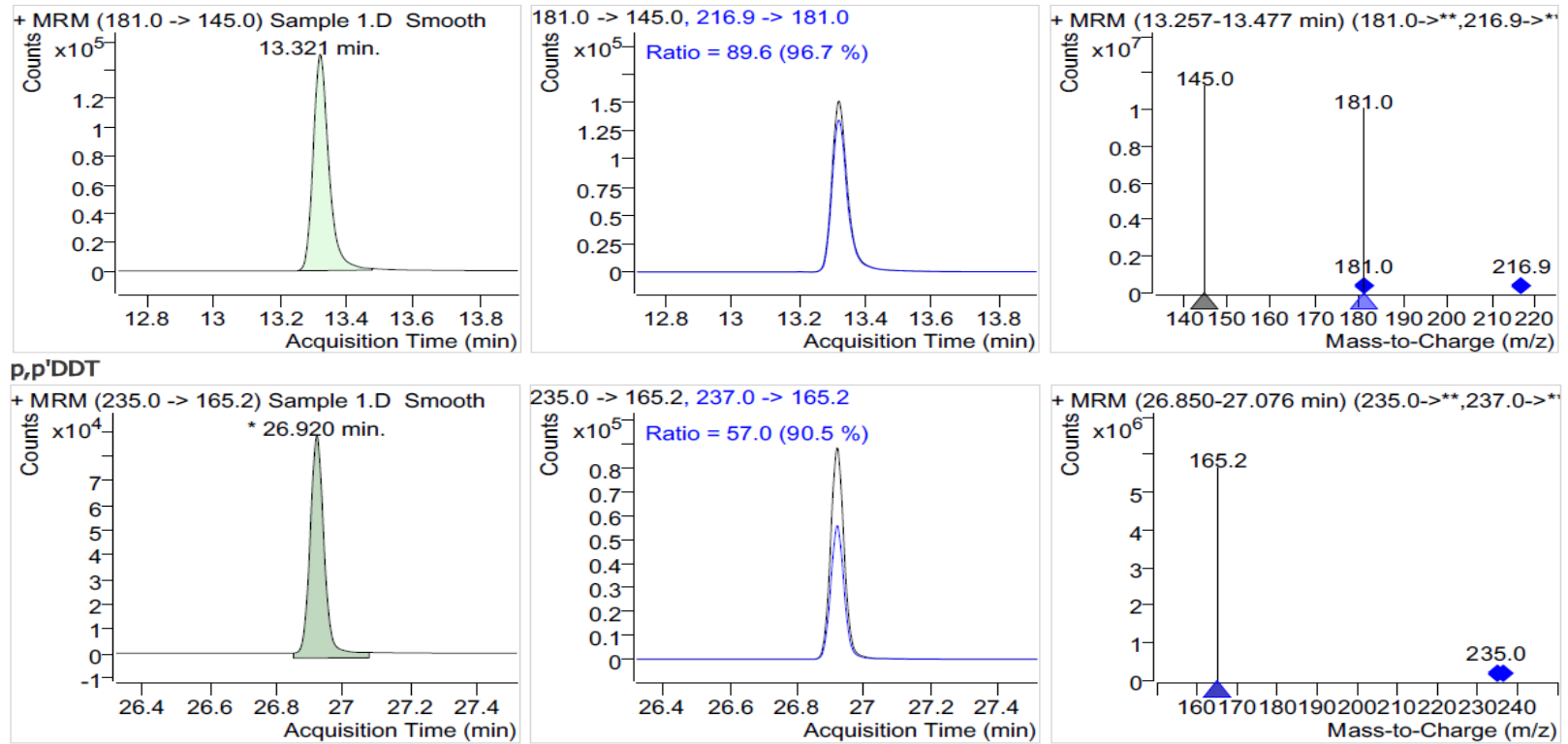

Figure 2 Gas Chromatograms and Mass Fingerprints of samples at $0 \mathrm{~h}$ incubation period (10PPM of DDT+Lindane)

Journal of Experimental Biology and Agricultural Sciences http://www.jebas.org 

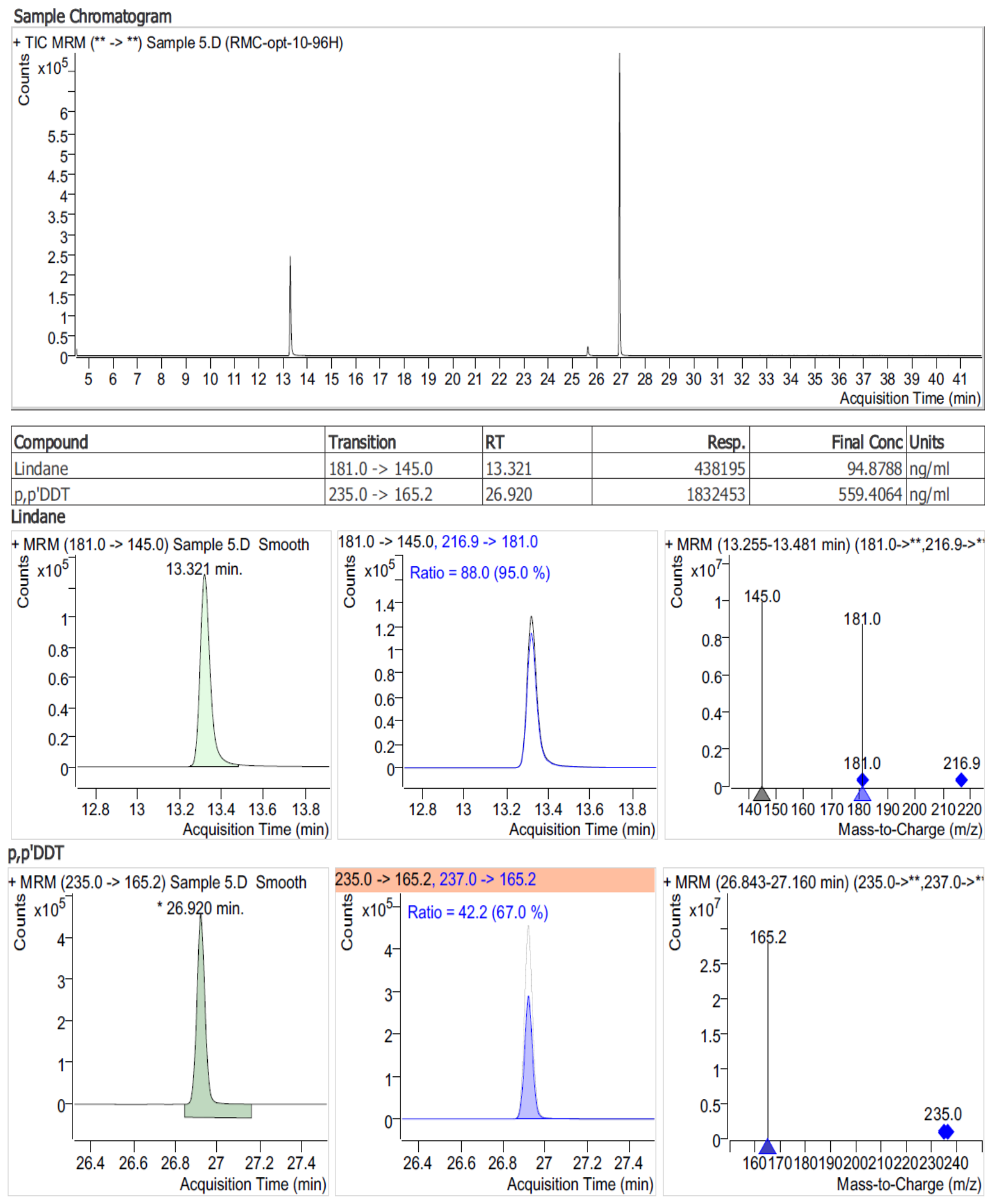

Figure 3 Gas Chromatograms and Mass Fingerprints of samples at $96 \mathrm{~h}$ incubation period (10PPM of DDT+Lindane) 
Sample Chromatogram

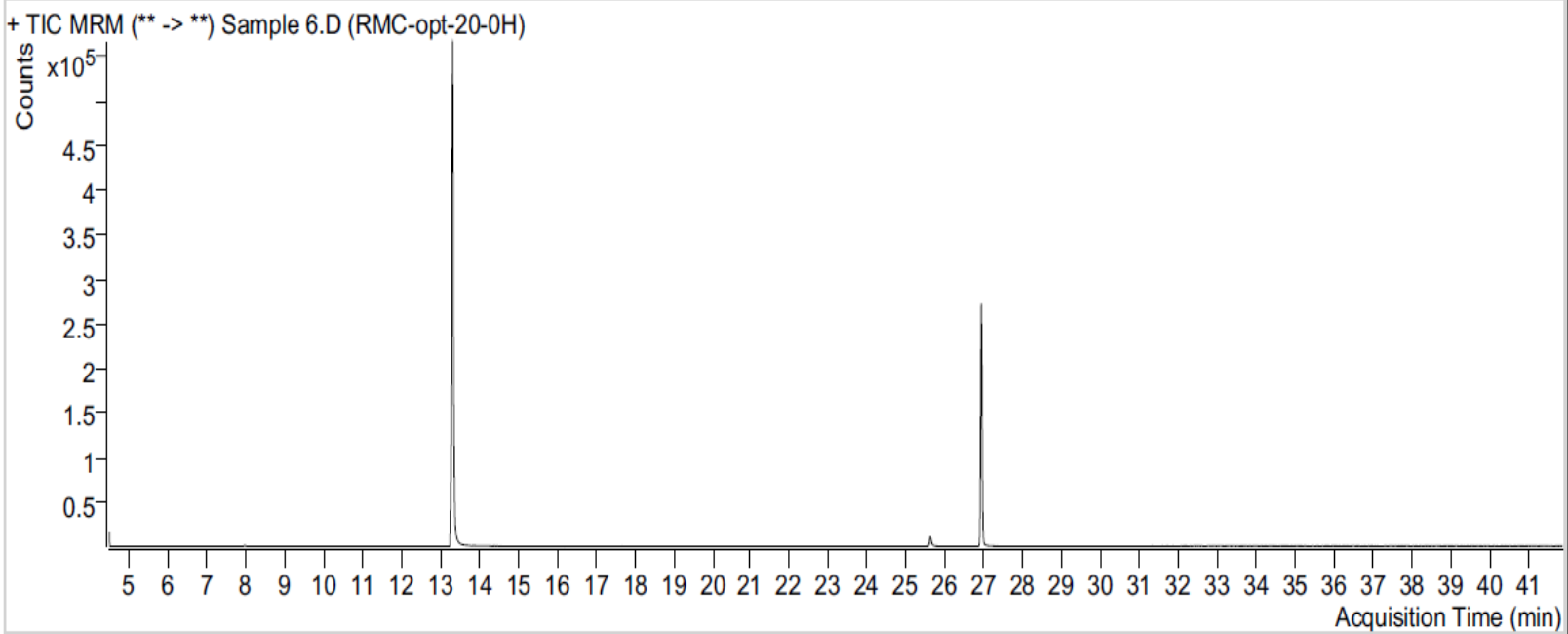

\begin{tabular}{|l|l|l|r|r|l|}
\hline Compound & Transition & RT & Resp. & Final Conc & Units \\
\hline Lindane & $181.0->145.0$ & 13.321 & 1231183 & 200.2645 & $\mathrm{ng} / \mathrm{ml}$ \\
\hline p,p'DDT & $235.0->165.2$ & 26.918 & 588712 & $192.1984 \mid \mathrm{ng} / \mathrm{ml}$ \\
\hline
\end{tabular}

Lindane

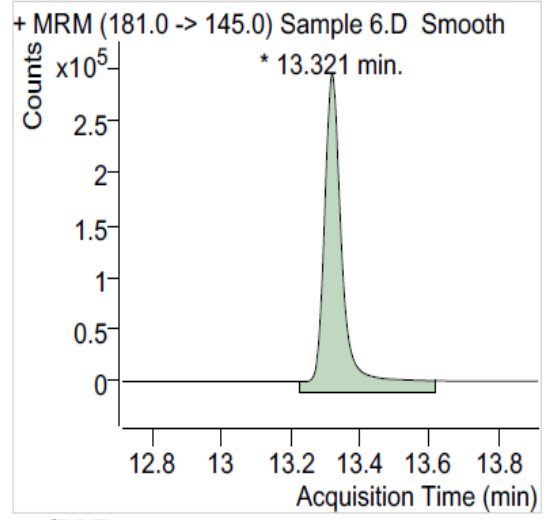

\section{p,p'DDT}

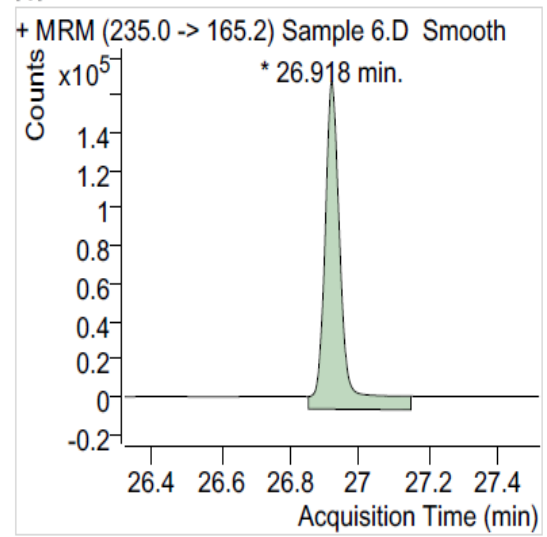

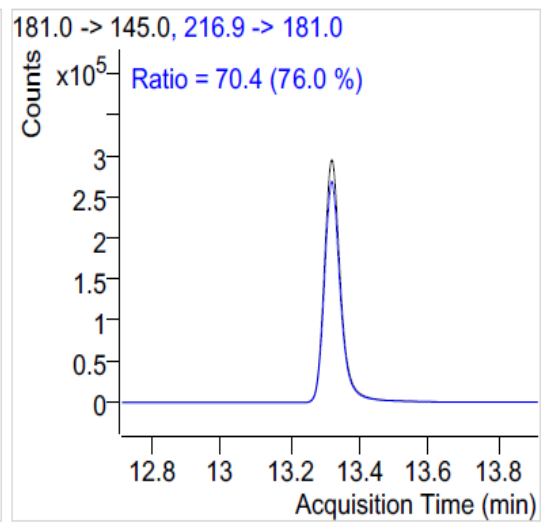
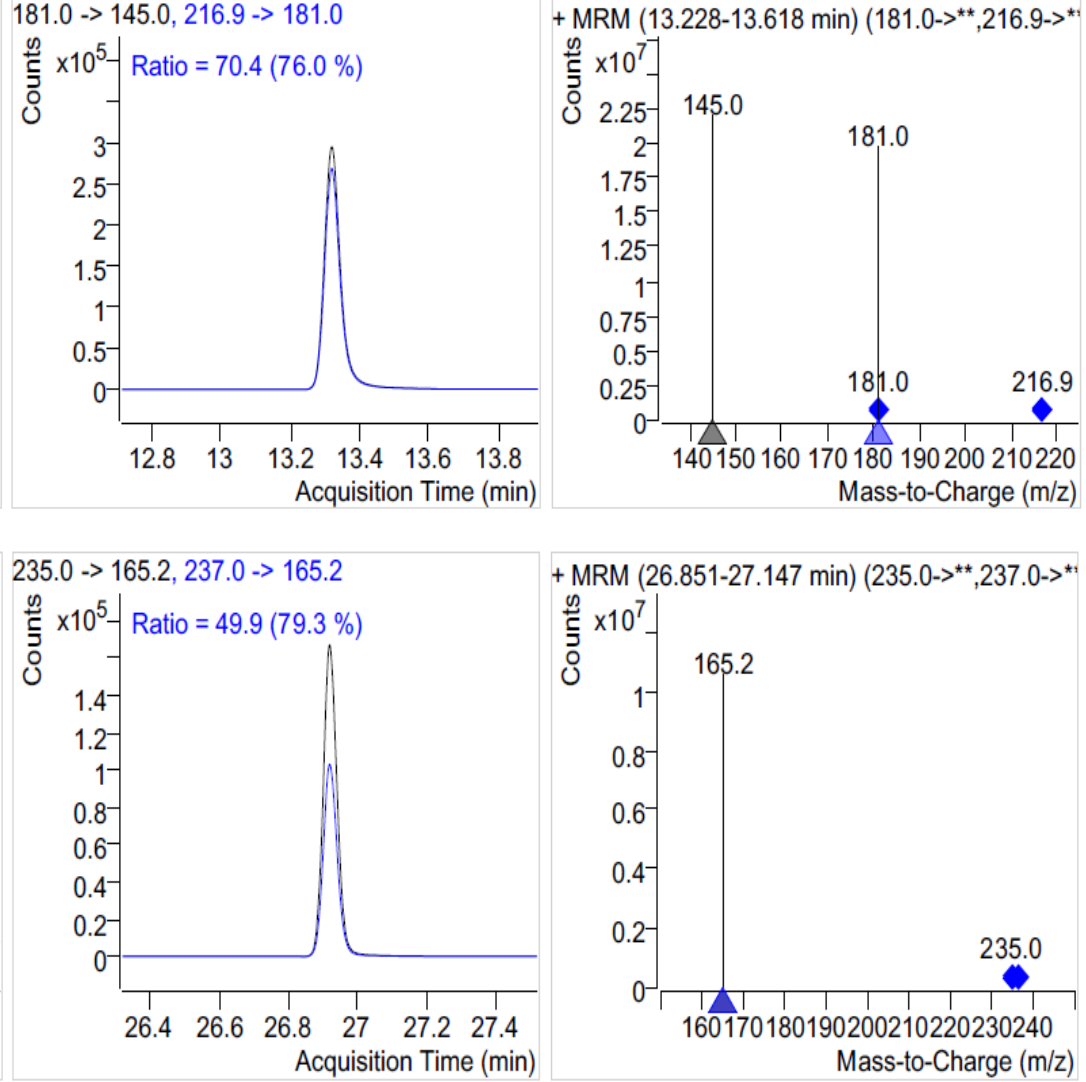

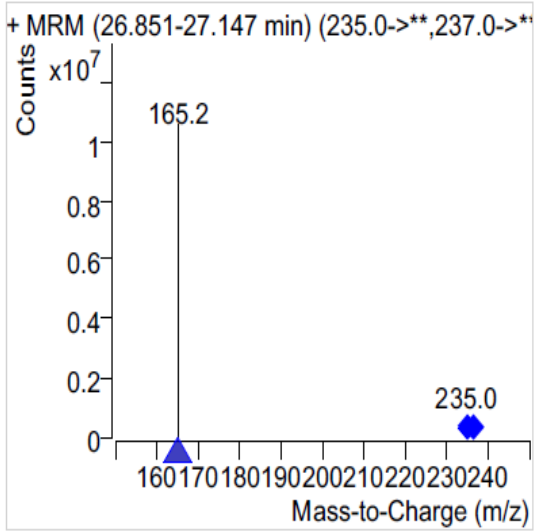

Figure 4 Gas Chromatograms and Mass Fingerprints of samples at $0 \mathrm{~h}$ incubation period (20PPMof DDT+Lindane)

Journal of Experimental Biology and Agricultural Sciences http://www.jebas.org 


\section{Sample Chromatogram}

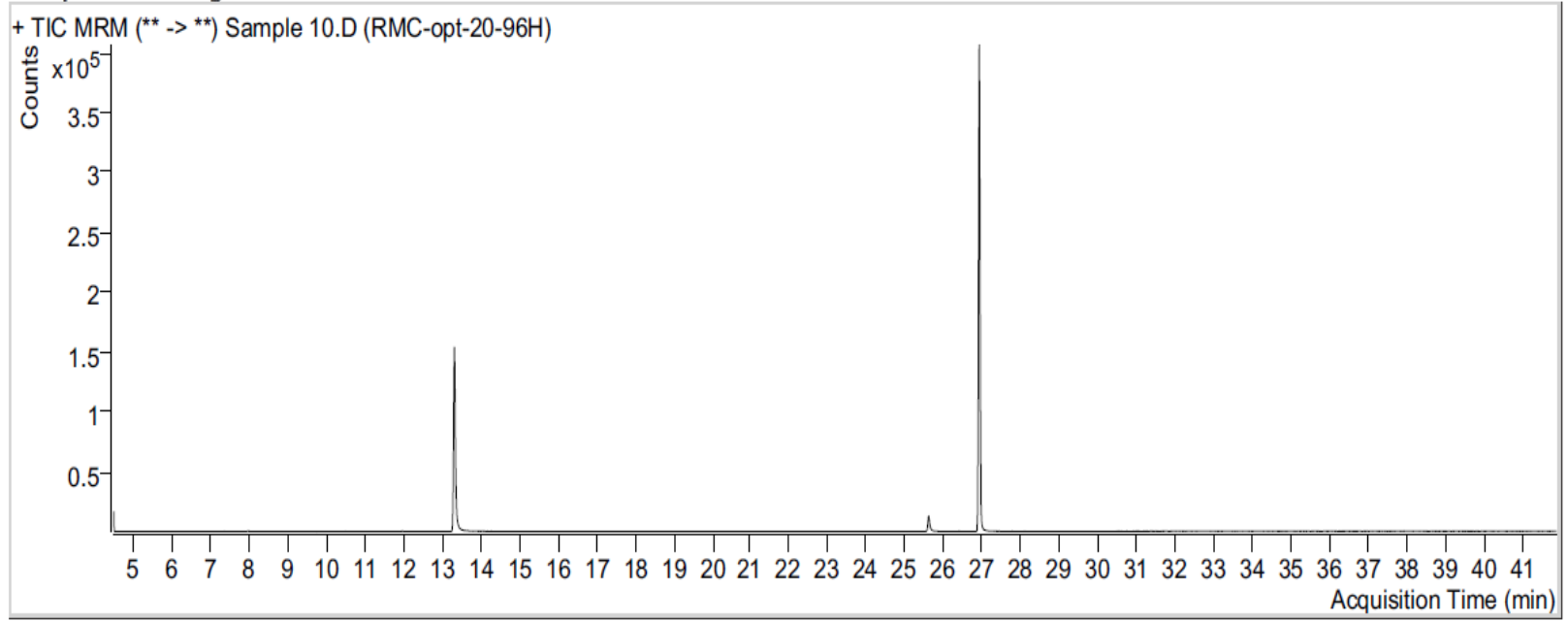

\begin{tabular}{|l|l|l|r|r|r|}
\hline Compound & Transition & RT & Resp. & Final Conc & Units \\
\hline Lindane & $181.0->145.0$ & 13.321 & 227041 & 66.8171 & $\mathrm{ng} / \mathrm{ml}$ \\
\hline p,p'DDT & $235.0->165.2$ & 26.919 & 978827 & 307.3777 & $\mathrm{ng} / \mathrm{ml}$ \\
\hline
\end{tabular}

\section{Lindane}
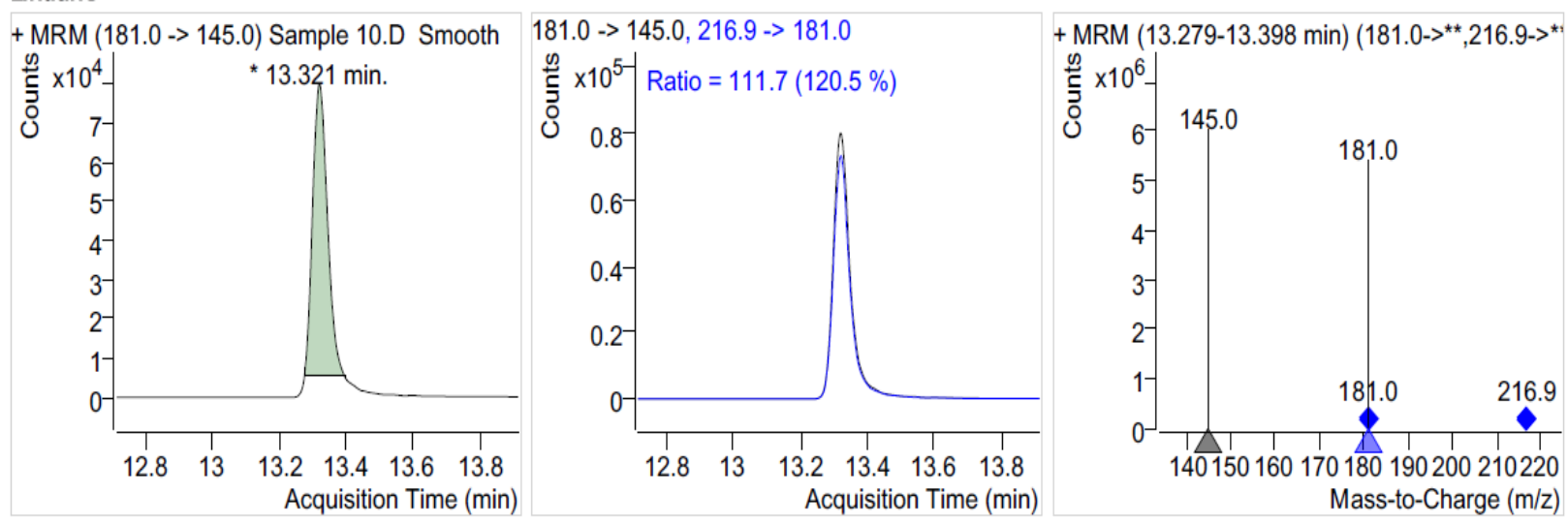

p,p'DDT
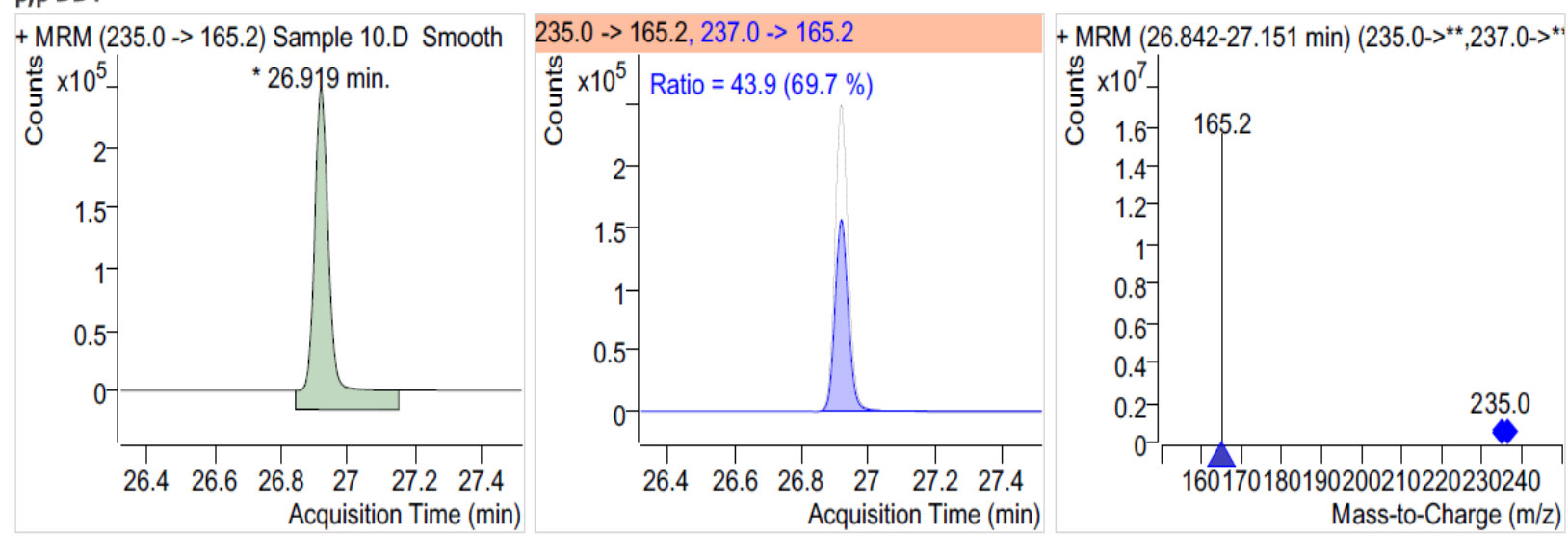

Figure 5 Gas Chromatograms and Mass Fingerprints of samples at 96H incubation period (20PPM of DDT+Lindane).

Journal of Experimental Biology and Agricultural Sciences http://www.jebas.org 


\section{Sample Chromatogram}

+ TIC MRM (** $>$ **) Sample11.D (RMC-opt-30-0H)

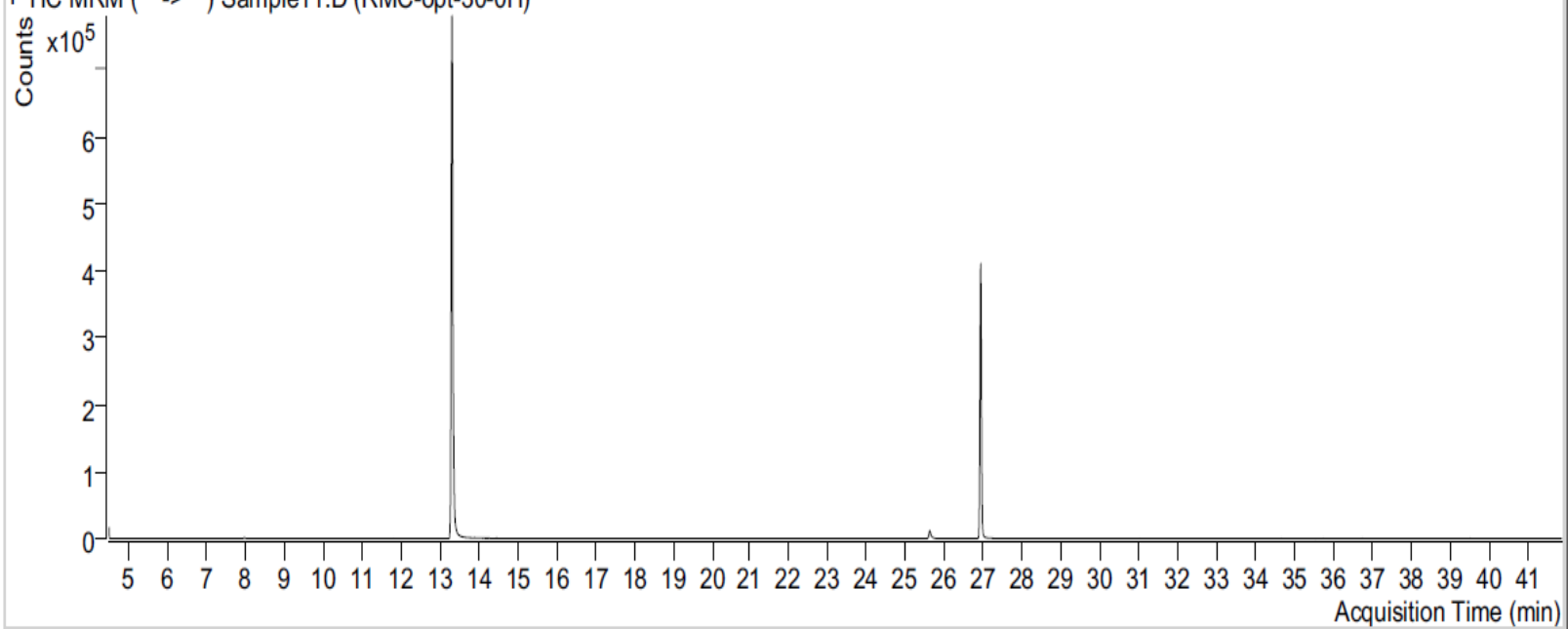

\begin{tabular}{|l|l|l|r|r|l|}
\hline Compound & Transition & RT & Resp. & Final Conc & Units \\
\hline Lindane & $181.0->145.0$ & 13.321 & 1919595 & 291.7523 & $\mathrm{ng} / \mathrm{ml}$ \\
\hline p,p'DDT & $235.0->165.2$ & 26.920 & 957681 & 301.1347 & $\mathrm{ng} / \mathrm{ml}$ \\
\hline
\end{tabular}

\section{Lindane}

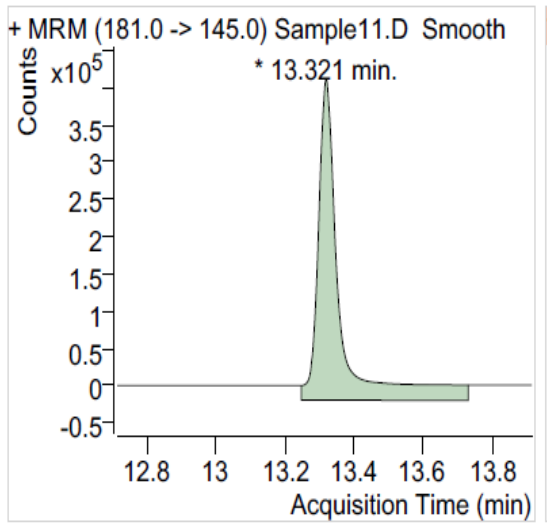

p,p'DDT

+ MRM (235.0 -> 165.2) Sample11.D Smooth

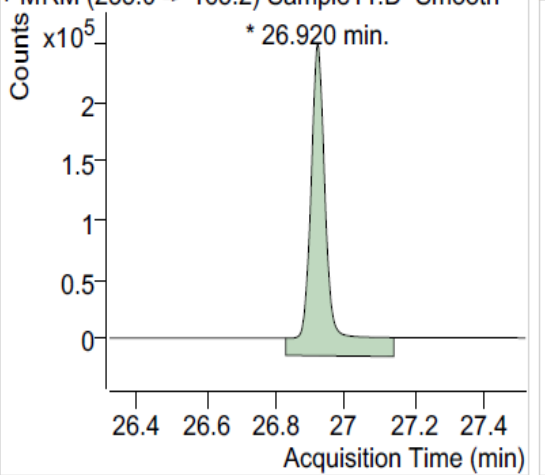

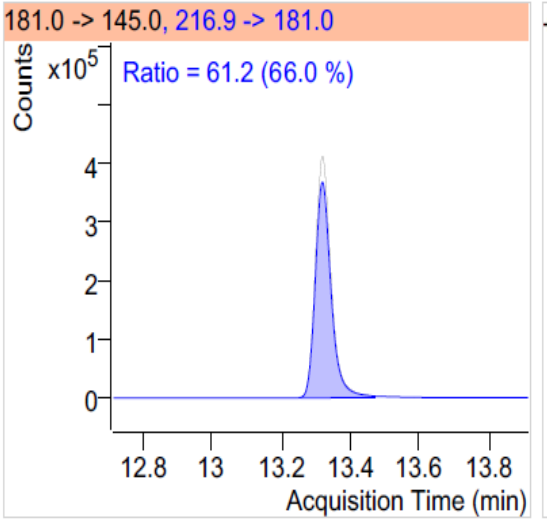

+ MRM (13.248-13.732 $\mathrm{min})\left(181.0->^{* *}, 216.9->^{*}\right.$
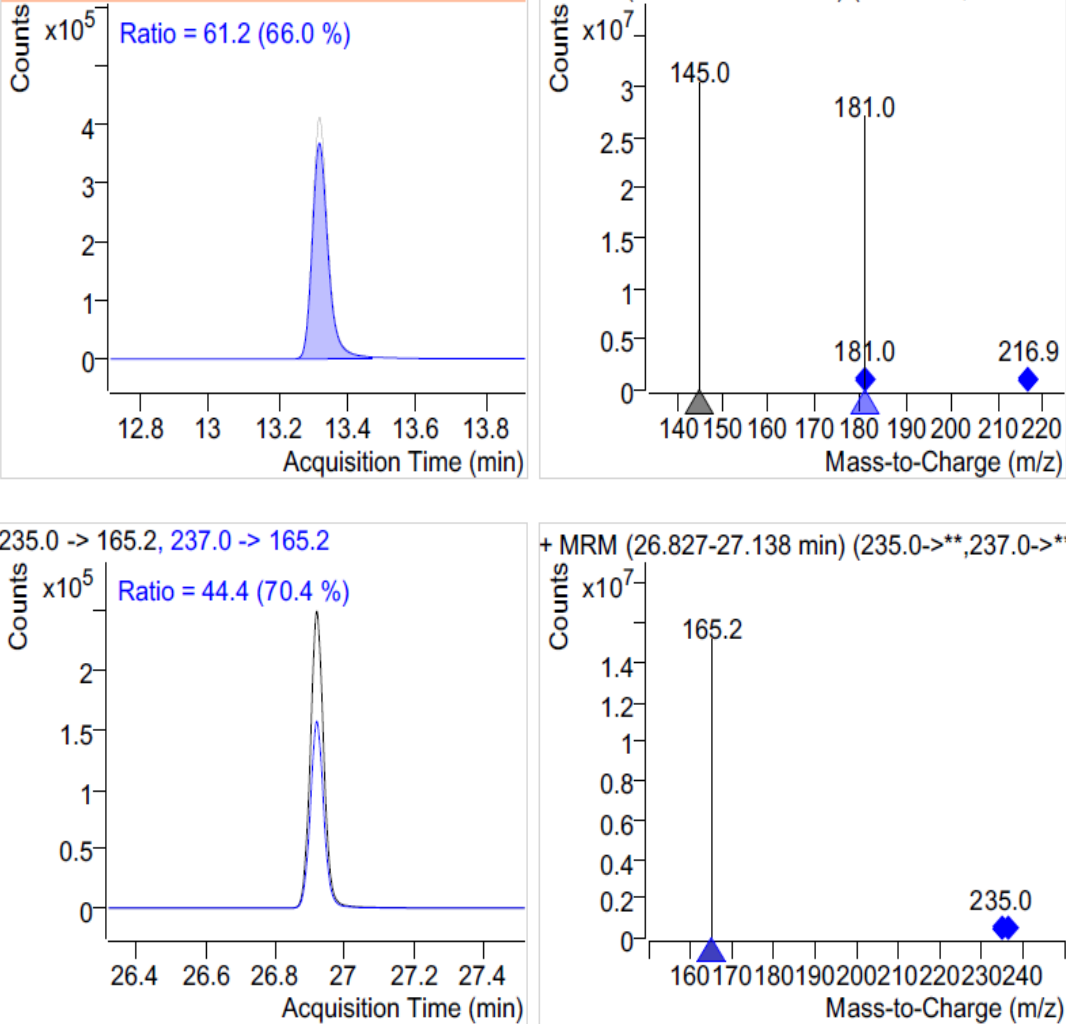

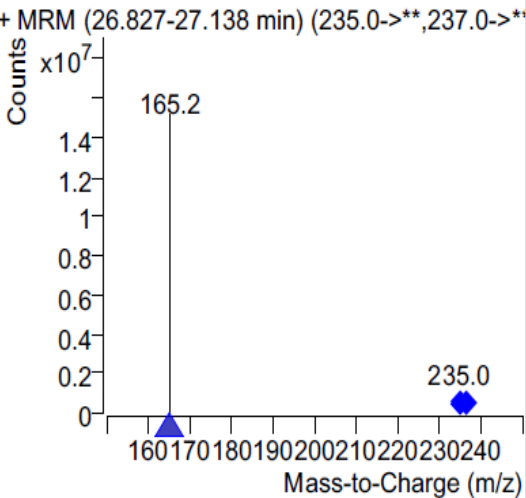

Figure 6 Gas Chromatograms and Mass Fingerprints of samples at $0 \mathrm{~h}$ incubation period (30PPM of DDT+Lindane).

Journal of Experimental Biology and Agricultural Sciences http://www.jebas.org 


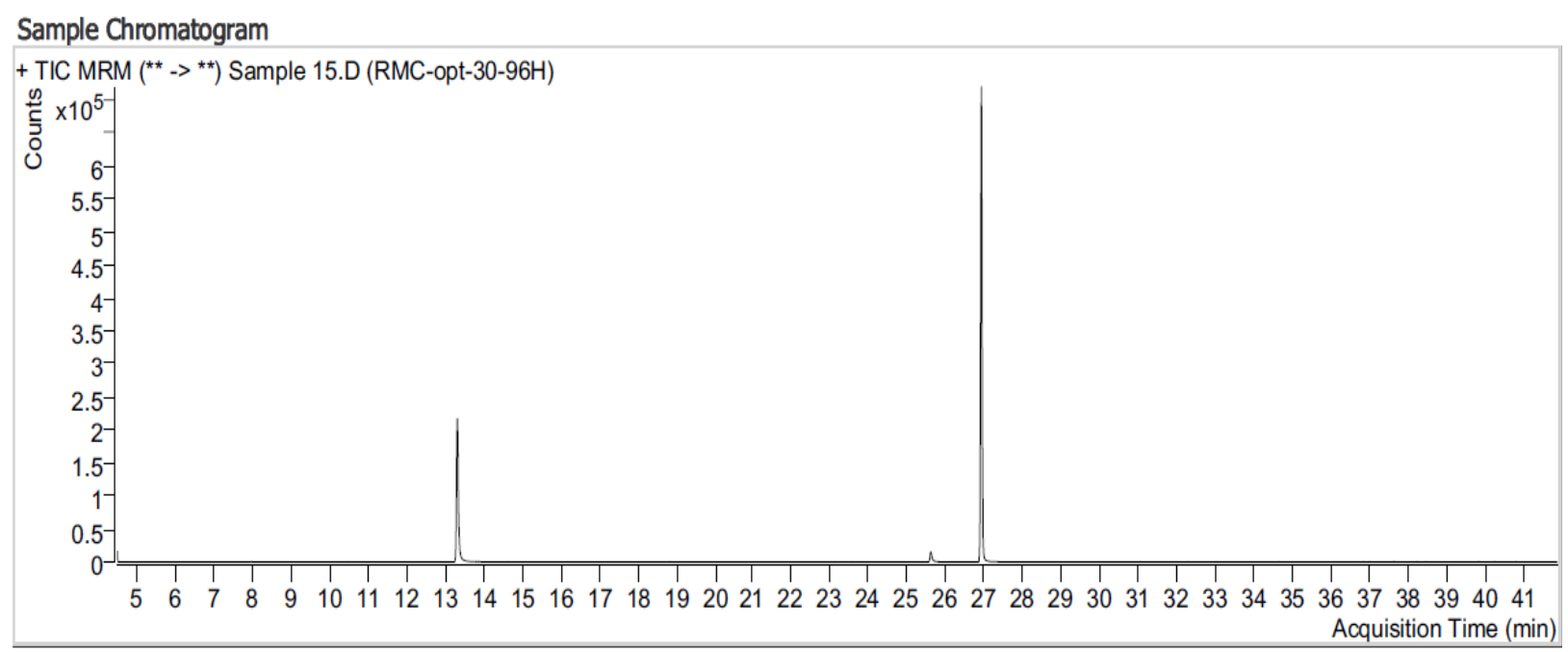

\begin{tabular}{|l|l|l|r|r|r|}
\hline Compound & Transition & RT & Resp. & Final Conc Units \\
\hline Lindane & $181.0->145.0$ & 13.321 & 473626 & $99.5875 \mathrm{ng} / \mathrm{ml}$ \\
\hline p,p'DDT & $235.0->165.2$ & 26.920 & 1612110 & $494.3512 \mathrm{ng} / \mathrm{ml}$ \\
\hline
\end{tabular}

\section{Lindane}

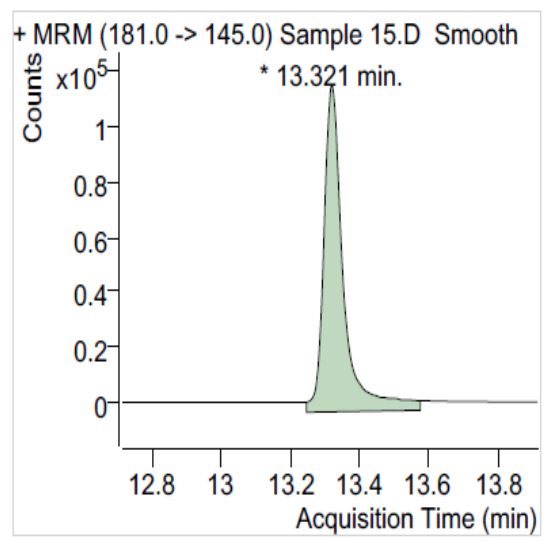

\section{p,p'DDT}
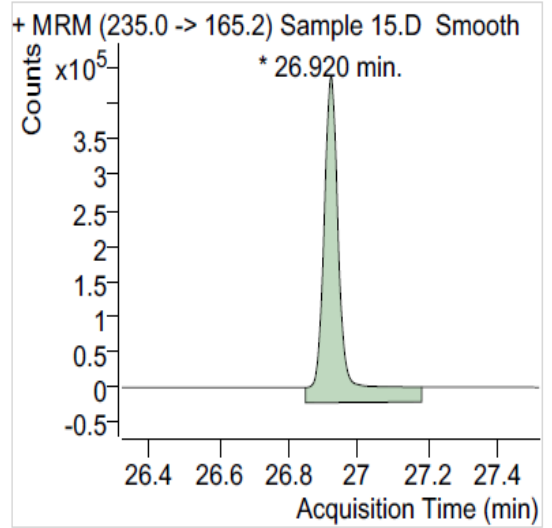
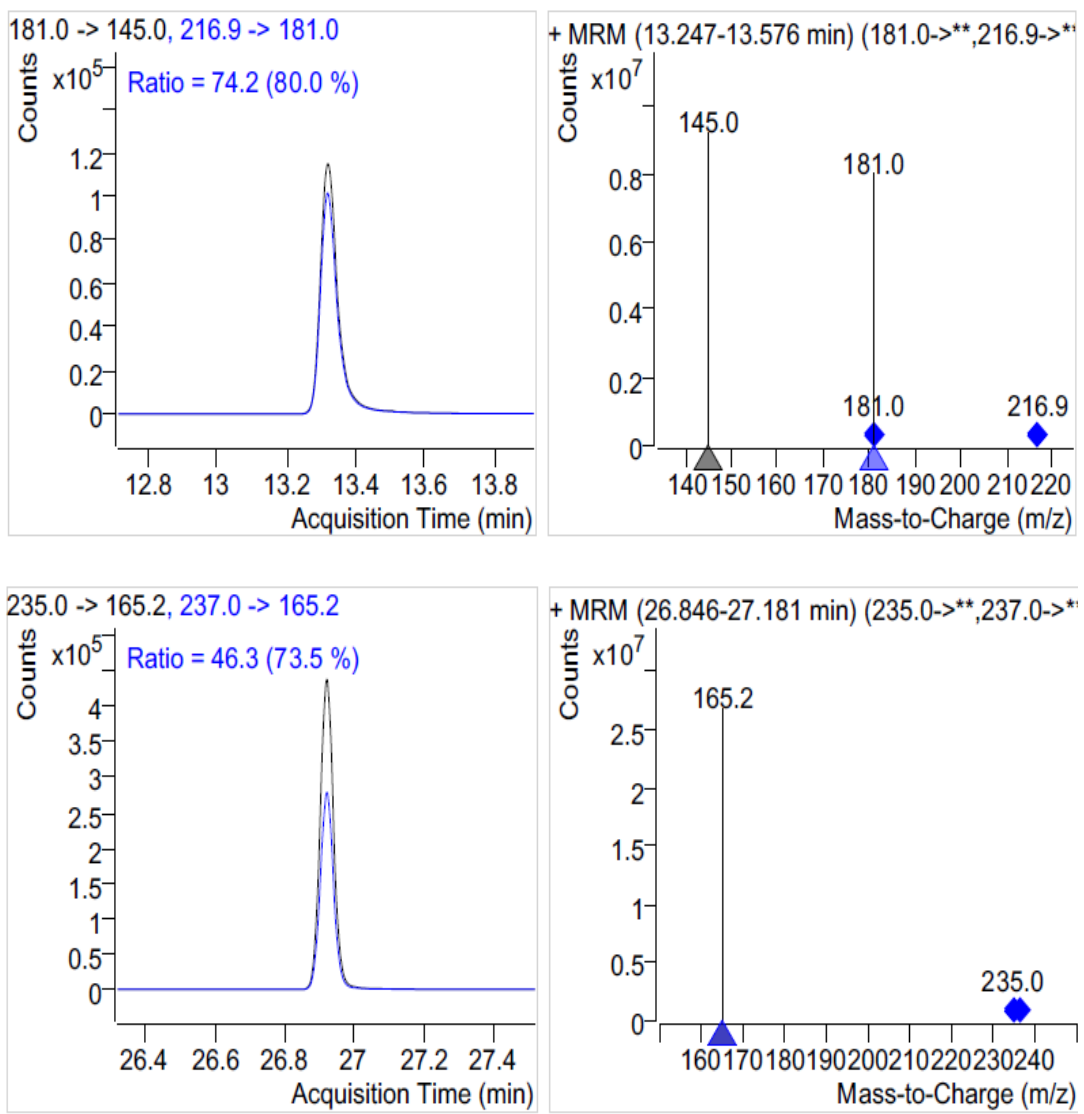

Figure 7 Gas Chromatograms and Mass Fingerprints of samples at $96 \mathrm{~h}$ incubation period (30PPMof DDT+Lindane).

Journal of Experimental Biology and Agricultural Sciences http://www.jebas.org 


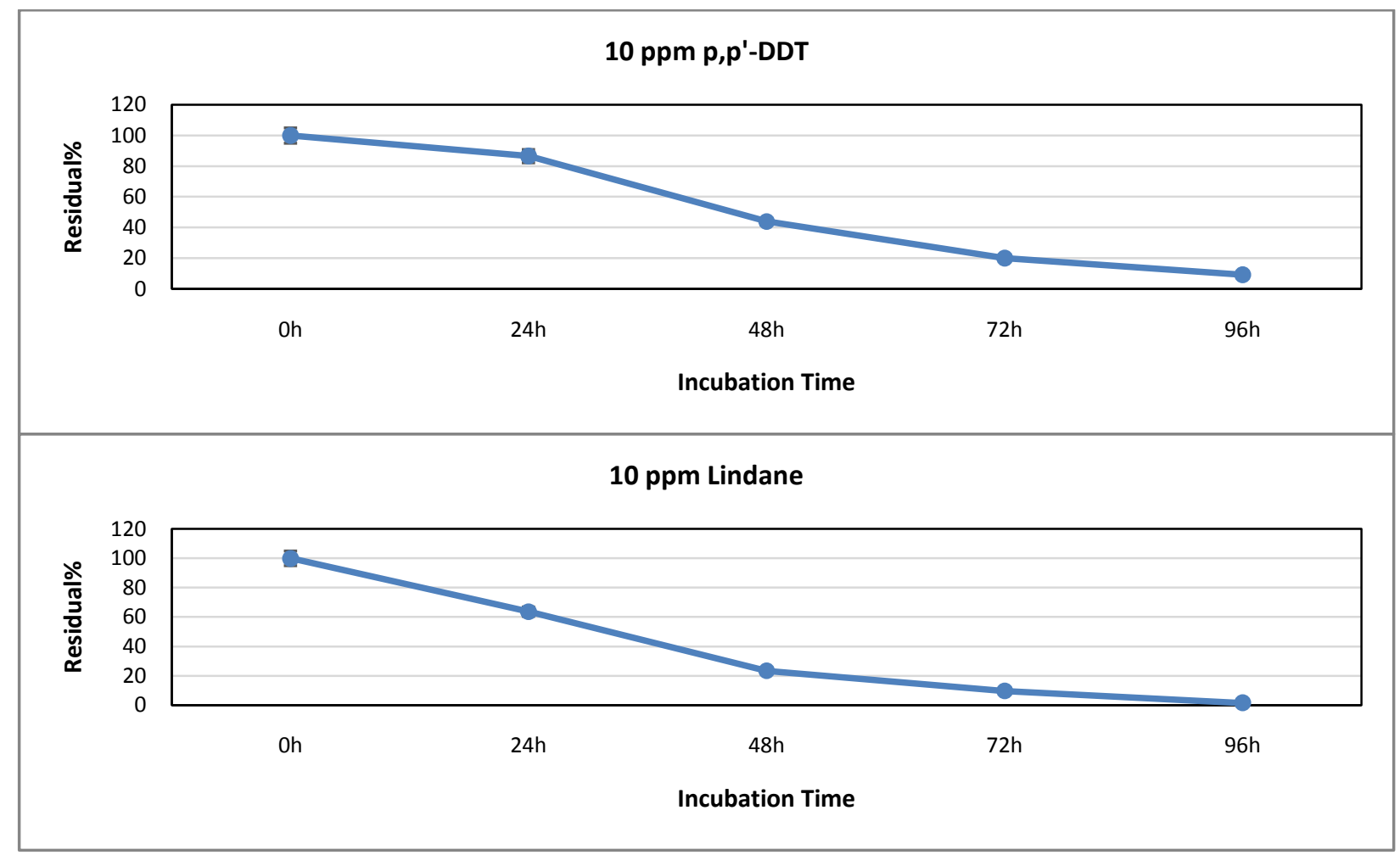

Figure 8 DDT and Lindane Degradation at 10 PPM Concentration

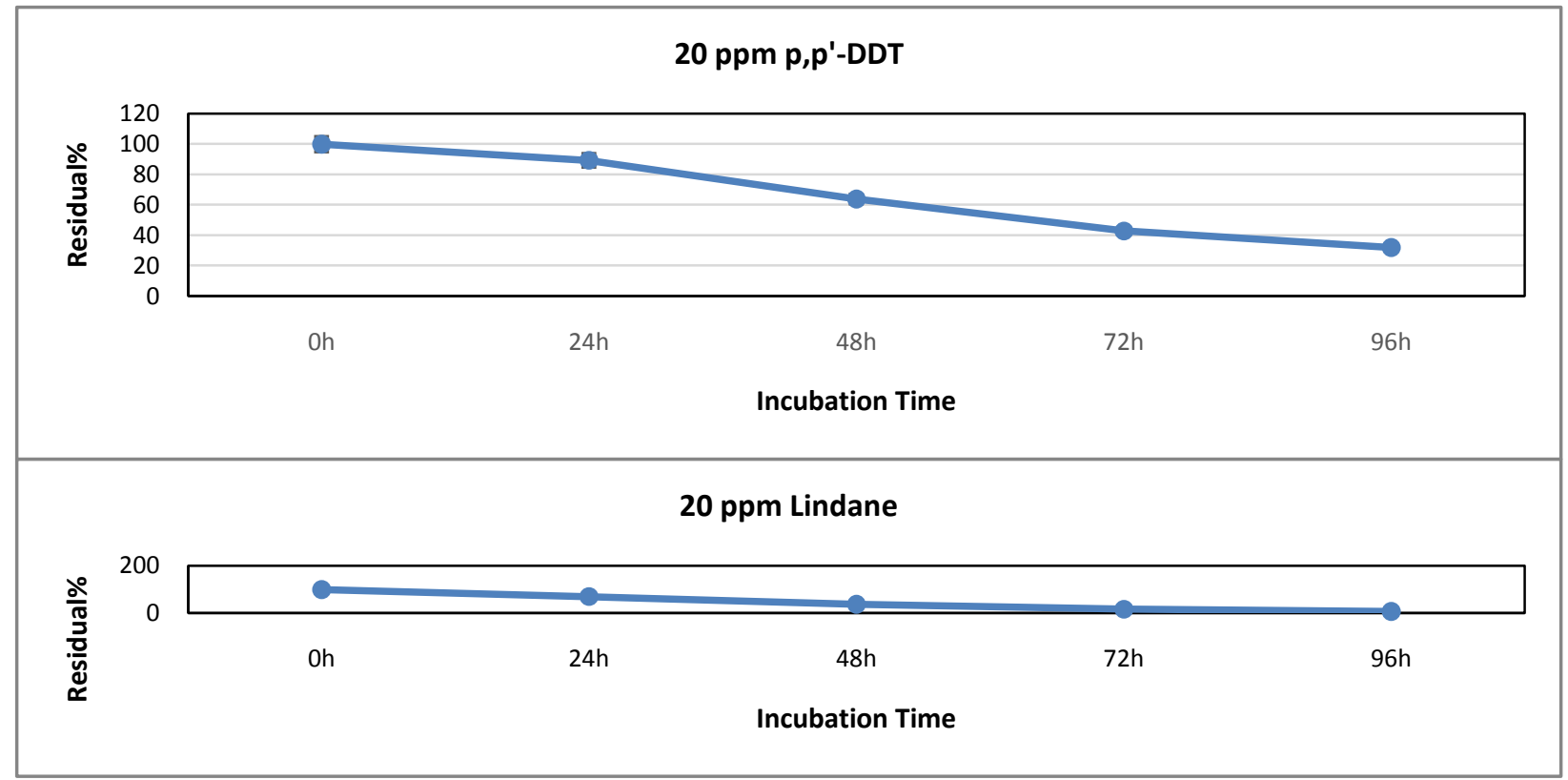

Figure 9 DDT and Lindane Degradation at 20 PPM Concentration

Journal of Experimental Biology and Agricultural Sciences http://www.jebas.org 


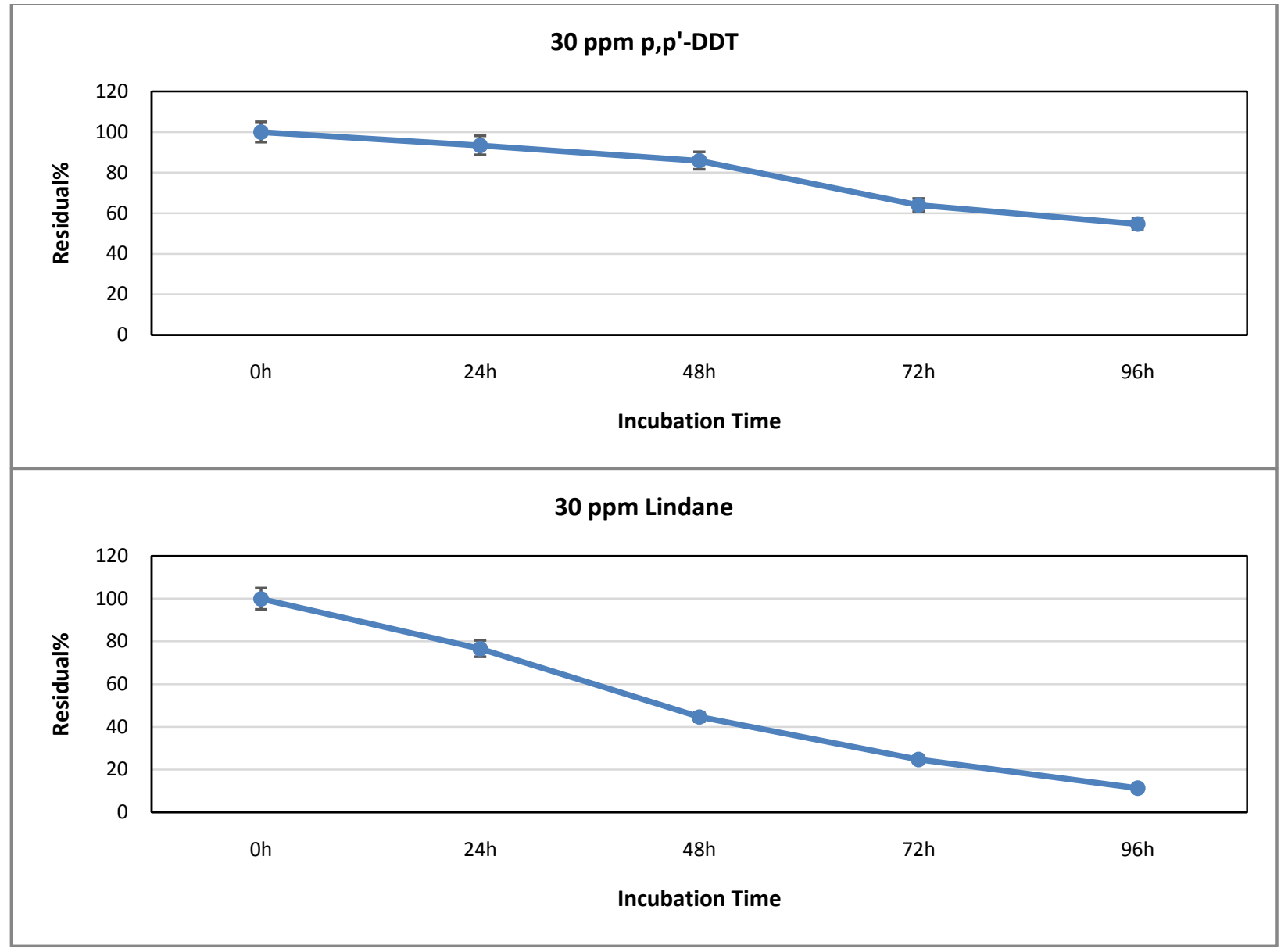

Figure 10 DDT and Lindane Degradation at 30 PPM Concentration

Table 1 Organisms Identified through Metagenomic Characterization by Hiseq2500, Illumina Platform, NGS

\begin{tabular}{|l|c|}
\hline Total Reads & $5,88,408$ \\
\hline Total number of stitched reads & $2,81,957$ \\
\hline Number of OTUs & 2,911 \\
\hline Abundant phylum & Proteobacteria \\
\hline Abundant class & Betaproteobacteria \\
\hline Abundant order & Burkholderiales \\
\hline Abundant family & Alcaligenaceae \\
\hline Abundant genus & Brevundimonas \\
\hline Abundant species & dimunita \\
\hline shannon alpha-diversity & 3.0317 \\
\hline Observed species & 871 \\
\hline
\end{tabular}

Journal of Experimental Biology and Agricultural Sciences http://www.jebas.org
The consortium identified is tabulated in Table 1. DNA sequences of the consortium capable of degrading the Organochlorine mixture have been deposited at National Center for Biotechnology Information (NCBI) Sequence Read Archive under the bioproject ID PRJNA420925 and accession code SRX348847.

\section{Conclusions}

Microbes are primary stimulants in the bioremediation of contaminated environments. The defined microbial consortium RMC tested for degrading mixture of organochlorine pesticides with concentrations up to $30 \mathrm{ppm}$ of DDT and Lindane. Biodiversity of microbial population with 871 prokaryotic species constituted the RMC. Although research has been carried out using on single strain and single compound of organochlorines, the current study data provides an insight on how bacterial communities in mixed consortia are taxonomically distributed and their biodiversity, the metagenomic characterization identified the consortium in a definitive manner which acts as promising 
solution for bioremediation of organochlorine mixtures. The microbial consortium (RMC) can be a viable strategy for remediation for organochlorine mixtures.

\section{Acknowledgements}

The authors would like to acknowledge Rayalaseema University and UGC for support and encouragement for the research studies.

\section{Conflict of Interest}

Authors would hereby like to declare that there is no conflict of interests that could possibly arise.

\section{References}

Abd El-Gawad H (2016) Validation method of organochlorine pesticides residues in water using gas chromatography-quadruple mass. Water Science 30: 96-107.

Abraham J, Silambarasan S, Logeswari P (2014) Simultaneous degradation of organophosphorus and organochlorine pesticides by bacterial consortium. Journal of the Taiwan Institute of Chemical Engineers 45: 2590-2596.

Bidlan R, Manonmani HK (2009) A process for the preparation of biocatalysts for the remediation of dichlorodiphenyldichloroethane (DDD/TDE) containing industrial effluents. Patent. 734/DEL/2005A, International Classification No. A01J.
Blomquist TM, Crawford EL, Lovett JL, Yeo J, Stanoszek LM(2013) Targeted RNA Sequencing with Competitive Multiplex-PCR Amplicon Libraries. PLOS ONE 8 : 10.1371.

De Muinck EJ, PålTrosvik, Gilfillan GD, Hov JR, Sundaram AYM (2017), A novel ultra-high-throughput 16S rRNA gene amplicon sequencing library preparation method for the Illumina HiSeq platform. Microbiome 5:68

Handelsman J (2004) Metagenomics: Application of Genomics to Uncultured Microorganisms. Microbiology and Molecular Biology Reviews 68:669-685.

Jayaraj R, Megha P, Sreedev P (2017) Organochlorine pesticides, their toxic effects on living organisms and their fate in the environment. Interdisciplinary Toxicology 9: 90-100.

Muir D, Sverko E (2006) Analytical methods for PCBs and organochlorine pesticides in environmental monitoring and surveillance: a critical appraisal. Analytical and Bioanalytical Chemistry 386:769-789.

Pandey P, Khillare PS, Kumar K (2011) Assessment of Organochlorine Pesticide Residues in the Surface Sediments of River Yamuna in Delhi, India. Journal of Environmental Protection 2: 511-524.

WasimAktar M, Sengupta D, Chowdhury A (2009) Impact of pesticides use in agriculture: their benefits and hazards. Interdisciplinary Toxicology 2:1-12. 